\title{
Texture and Microstructure of Some Low Alloy Steels Containing $\mathrm{Nb}$ and $\mathrm{B}$
}

\author{
C. S. C. VIANA, P. R. RIOS and L. P. M. BRANDÃO \\ Seção de Engenharia e Ciência dos Materials, Instituto Militar de Engenharia, \\ Praça General Tibúrcio 80, URCA, Rio de Janeiro, RJ, 22290, Brazil
}

(Received July 16, 1987)

\section{Dedicated to the memory of Professor Günter Wassermann}

In the present work the textures and the microstructures of some controlled rolled low carbon steels containing $\mathrm{Nb}$ and $\mathrm{B}$ were correlated to their boron content. This varied from 5 to $21 \mathrm{ppm}$ and had the effect of replacing polygonal ferrite in the lower B-content steels by bainitic ferrite in the higher B-content ones. The grain size decreased from $\sim 3 \mu \mathrm{m}$ in the former to $1 \mu \mathrm{m}$ in the latter. The texture became correspondingly stronger as the transformation mechanism changed from diffusional to shear mode. Considering that the rolling schedule and cooling rate (air) were the same for all steels the textural and microstructural changes are attributed to the change in boron content.

KEY WORDS: Low carbon steels, boron content, ODF-analysis, TEM-analysis, controlled rolling.

\section{INTRODUCTION}

In the last decades the controlled rolling of high strength microalloyed steels has been capable of responding to most needs of gas and oil pipeline fabrication. Severe rolling, low finish rolling temperature and on-line accelerated cooling have been the main tools for attaining the required properties. In many cases, low temperature transformation products such as acicular ferrite, bainite and martensite are obtained, the fineness of their microstructural 
features depending on composition as well as on processing variables.

In general, the pancake unrescrystallized austenite grains resulting from the large reductions imposed by the controlled rolling display a texture with the copper-type preferred orientations (Davies and Kallend, 1976, Davies and Bateman, 1981). On transformation, the products may also show a texture, with components near to $\{\overline{1} 13\}\langle\overline{1} \overline{1} 0\rangle$ and $\{\overline{3} 32\}\langle 1 \overline{1} 3\rangle$, inherited from that of the austenite through the Kurdjumov-Sachs or NishiyamaWassermann orientation relationships, in which all or some variants are said to be operative (Davies and Bateman, 1981, Bateman and Davies, 1981, Yutori and Ogawa, 1981).

A recent development in high strength and toughness materials for line pipes is represented by the low carbon steels containing niobium and boron (Hulka et al.). These steels are strengthened in the as-rolled condition by a combination of dislocation hardening and ultra-fine grain size via the use of $\mathrm{Nb}$ to retard recrystallization of the deformed austenite and B to depress the transformation temperature.

In the present work the textures and microstructures of some controlled rolled $\mathrm{B}+\mathrm{Nb}$ microalloyed steels are analysed as a function of their boron content and the character of their phase transformation.

\section{EXPERIMENTAL PROCEDURE}

The compositions of the steels are shown in Table 1. Vacuum melting and casting was used in order to obtain low levels of impurities and interstitials.

Table 1 Composition in wt.\%. For all steels $\mathrm{P}, \mathrm{S}<0.005 ; \mathrm{Al} \sim 0.020$; $\mathrm{Ti} \sim 0.015$ and $\mathrm{N} \sim 0.0020$

\begin{tabular}{lllllll}
\hline Steel & $\mathrm{C}$ & $\mathrm{Si}$ & $\mathrm{Mn}$ & $\mathrm{Cr}$ & $\mathrm{Nb}$ & $\mathrm{B}(\mathrm{ppm})$ \\
\hline $\mathrm{A}$ & 0.032 & 0.30 & 1.62 & - & 0.089 & 5 \\
B & 0.030 & 0.30 & 1.62 & - & 0.090 & 9 \\
$\mathrm{C}$ & 0.027 & 0.30 & 1.63 & - & 0.093 & 16 \\
$\mathrm{D}$ & 0.024 & 0.32 & 1.65 & 0.32 & 0.090 & 20 \\
E & 0.031 & 0.33 & 1.96 & 0.33 & 0.107 & 21 \\
\hline
\end{tabular}


Table 2 Applied rolling schedule

\begin{tabular}{llllll}
\hline Soaking & $\begin{array}{l}\text { Slab } \\
\text { thickness }\end{array}$ & $\begin{array}{l}\text { Intermediate } \\
\text { deformation } \\
\text { temperature }\end{array}$ & $\begin{array}{l}\text { Final } \\
\text { thickness }\end{array}$ & $\begin{array}{l}\text { Finish } \\
\text { rolling } \\
\text { temperature }\end{array}$ & Cooling \\
\hline $1180^{\circ} \mathrm{C}$ & $200 \mathrm{~mm}$ & $970^{\circ} \mathrm{C}$ & $18 \mathrm{~mm}$ & $800^{\circ} \mathrm{C}$ & air \\
\hline
\end{tabular}

The materials were controlled rolled using the technique of inserting the experimental ingots within windows cut into a steel slab (Hulka et al.). Table 2 shows some data of the rolling schedule used for all the steels.

Optical and transmission electron microscopy as well as quantitative metallography were used to analyse the microstructures. The mean intercept length grain sizes were measured on longitudinal sections using, whenever possible, both optical and TEM techniques.

In order to detect the presence of martensite a metabisulfite based tint etching was used. Details of the techniques of microstructural analysis can be found elsewhere (Rios, 1986). The texture was quantified via the crystallite orientation distribution function (CODF) using the method developed by Roe (1965).

Full thickness specimens for texture measurement were sliced from the plate using the geometry of Lopata and Kula (1962). Three complete pole distributions were measured and the CODF series coefficients were used up to $l=20$ to calculate the texture severity parameter (TSP). This is the standard deviation of the orientation distribution function from uniformity and is given by (Bunge 1969, Kallend 1970):

$$
(\mathrm{TSP})=4 \sqrt{2} \pi^{2}\left(\sum_{1=1}^{\infty} \sum_{m=-1}^{1} \sum_{n=-1}^{1} W_{1 m n}^{2}\right)^{1 / 2}
$$

where $W_{1 m n}$ are the series coefficients.

\section{RESULTS}

\subsection{Microstructure}

The microstructure of the steels changed from polygonal ferrite (steel A) to bainitic ferrite (steels D and E) with increasing boron 


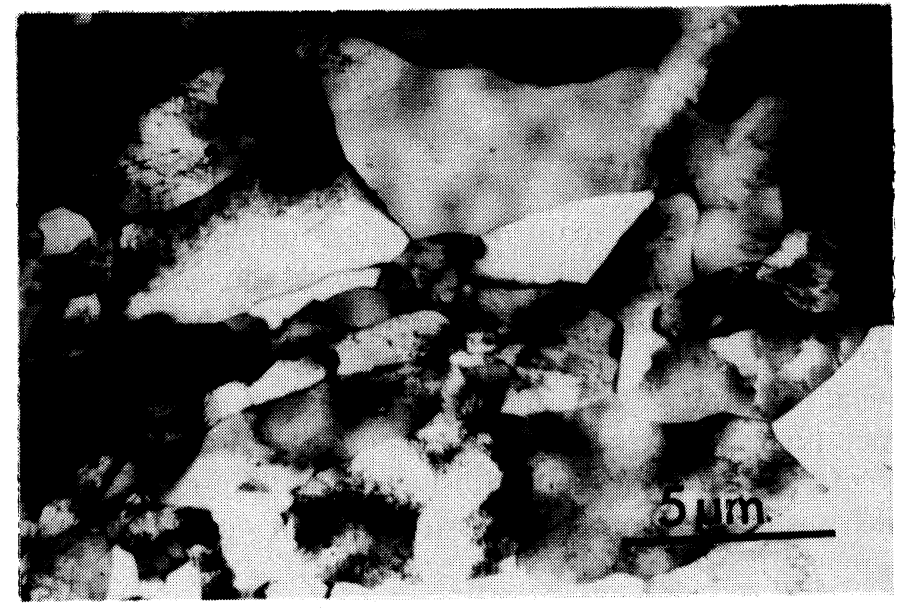

(a)

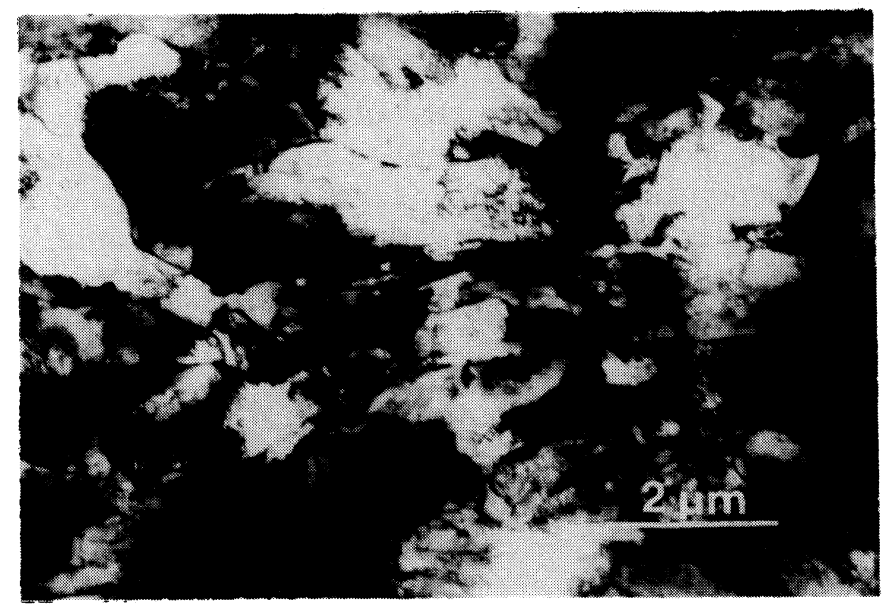

(b)

Figure 1 TEM micrographs of (a) steel A and (b) steel D. 
Table 3 Quantitative metallography results

\begin{tabular}{|c|c|c|c|}
\hline Steel & \multicolumn{2}{|c|}{ Grain size $(\mu \mathrm{m})^{*}$} & $\begin{array}{l}\text { Martensite } \\
\text { (vol.\%) }\end{array}$ \\
\hline $\mathbf{A}$ & 3.6 & 3.2 & 0.3 \\
\hline B & 3.3 & - & 1.4 \\
\hline $\mathbf{C}$ & 2.5 & 2.3 & 1.0 \\
\hline D & - & 1.0 & 3.0 \\
\hline $\mathbf{E}$ & - & - & 5.1 \\
\hline
\end{tabular}

* Mean intercept length on the longitudinal section.

content. Figures $1 \mathrm{a}$ and $1 \mathrm{~b}$ show the TEM micrographs of steels $\mathrm{A}$ and $\mathrm{D}$, respectively. It can be seen that the grain size of $A$ is larger than that of $\mathrm{D}$ and that the dislocation density is apparently higher in the latter.

Table 3 contains the data from the quantitative metallography analysis. One sees that all steels have very small grain sizes and that these decrease from about $3 \mu \mathrm{m}$ to $1 \mu \mathrm{m}$ as the boron content increases from $5 \mathrm{ppm}$ to $20 \mathrm{ppm}$. The microstructure of steels $\mathrm{D}$ and E could not be resolved by optical metallography. Therefore, TEM measurements of grain size had to be made. A small amount of martensite revealed by the metabisulfite tint etching was found in all materials and tended to reach higher values in the steels with the highest boron content.

\subsection{Texture}

Figures $2 \mathrm{a}$ and $2 \mathrm{~b}$ show the $\phi=0^{\circ}$ and $\phi=45^{\circ}$ sections of the CODF for steels A and D, respectively. These figures are plotted by contours of iso-probability, in times-random units, starting with the broken line for the random value $(=1)$, with increments of one.

The textures can be described as tubes of orientations running from $\{001\}\langle\overline{1} \overline{1} 0\rangle$ to $\{\overline{1} 12\}\langle\overline{1} \overline{1} 0\rangle$ and $\{\overline{6} 65\}\langle 1 \overline{4} 6\rangle$, for steel $A$, and to $\{\overline{2} 25\}\langle\overline{1} 1 \overline{0}\rangle$ and $\{\overline{3} 32\}\langle 1 \overline{1} 3\rangle$, for steel $D$. Table 4 shows the main components of the textures with corresponding maximum function heights (MFH) and texture severity parameters (TSP). It can be seen that both the MFH and TSP increase with increasing boron content. Also the textures show a slight shift of the orientations $\{\overline{1} 12\}\langle\overline{1} \overline{1} 0\rangle$ and $\{\overline{6} 65\}\langle 1 \overline{4} 6\rangle$, in steels $A$ and $B$, to $\{\overline{2} 25\}\langle\overline{1} \overline{1} 0\rangle$ and $\{\overline{3} 32\}\langle 1 \overline{1} 3\rangle$, respectively, in steels $\mathrm{C}, \mathrm{D}$ and $\mathrm{E}$. 

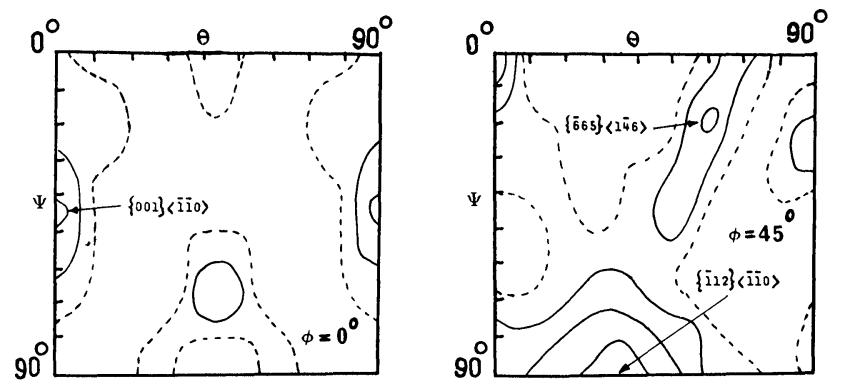

(a)
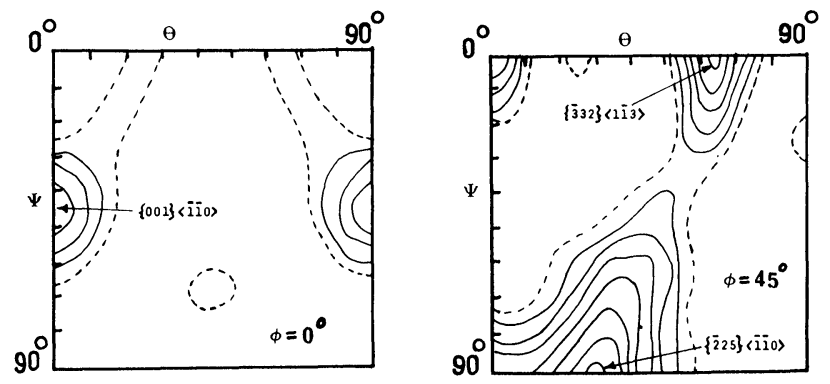

(b)

Figure $2 \phi=0^{\circ}$ and $\phi=45^{\circ}$ sections of the CODF for (a) steel A and (b) steel I

Table 4 Texture Severity Parameter

\begin{tabular}{|c|c|c|c|}
\hline Steel & $\begin{array}{l}\text { Main } \\
\text { orientations }\end{array}$ & $\begin{array}{l}\text { Maximum } \\
\text { function height (MFH) }\end{array}$ & TSP \\
\hline A & $\begin{array}{l}\overline{1} 12 \overline{1} \overline{1} 0 \\
6651 \overline{4} 6\end{array}$ & $\begin{array}{l}4.6 \\
3\end{array}$ & 0.8 \\
\hline B & $\begin{array}{l}\overline{1} 12 \overline{1} 10 \\
\overline{6} 65 \underline{1} \underline{4} 6\end{array}$ & $\begin{array}{l}7.1 \\
4\end{array}$ & 1.3 \\
\hline C & $\overline{2} 251 \overline{1} 10$ & $\begin{array}{l}8.4 \\
5\end{array}$ & 1.6 \\
\hline D & $\begin{array}{l}225110 \\
33211\end{array}$ & $\begin{array}{l}8 \\
6\end{array}$ & 1.6 \\
\hline $\mathrm{E}$ & $\overline{3} 3251 \overline{1} 10$ & $\begin{array}{l}8.5 \\
7\end{array}$ & 1.7 \\
\hline
\end{tabular}

TSP-Texture Severity Parameter. 


\section{DISCUSSION}

The decrease in grain size from steel A to steel D (Table 3) and the higher dislocation density of the latter suggest that the transformation correspondingly changed from diffusional to a shear mode. In other words, the product of the $\gamma-\alpha$ transformation changed from polygonal to bainitic ferrite. This is consistent with the increase in boron content as it is well known that this element strongly retards the polygonal ferrite nucleation thus promoting the formation of bainite (Maitrepierre, Thivellier and Tricot, 1975). The higher martensite volume fraction in steels $D$ and $E$ may be regarded as a further indication of this effect although the presence of a higher manganese content also contributes to martensite formation in these steels.

The same conclusion can be drawn from observation of the texture parameters in Table 4 (MFH and TSP) and from Figures 2a and $2 \mathrm{~b}$. The texture components are characteristic of transformation textures (Davies and Kallend, 1976, Davies and Bateman, 1981, Bateman and Davies, 1981, Yutori and Ogawa, 1981). The increase in MFH and TSP indicate a shift of the transformation towards shear mechanisms, in agreement with the results of Yutori and Ogawa (Yutori and Ogawa, 1981). These authors showed that products resulting from shear transformations display stronger textures than those resulting from diffusion controlled ones. According to Yutori and Ogawa's classification of the transformation, based on the MFH in the $\{\overline{3} 32\}\langle 1 \overline{1} 3\rangle$ orientation, in steels A and B underwent a diffusion mode transformation while steel $C$ went through a mixed mode and steels $D$ and $F$ transformed by a shear mechanism. Yutori and Ogawa (1981) as well as Davies and Bateman (1981) showed evidence that variant selection also contributes to texture enhancement and sharpness and that selection is more likely to occur in microstructures resulting from deformed rather than undeformed austenite.

In the present work all the steels underwent the same rolling schedule and cooling rate, and, since the $\mathrm{Nb}$ content is nearly constant, recrystallization was retarded in pretty much the same manner in all of them.

Therefore, the variable that can be associated with the texture build up is the boron content (or possibly a $\mathrm{Nb}+\mathrm{B}$ effect). This 
effect is similar to increasing the cooling rate and, in fact, even for low carbon contents and air cooling, is capable of producing textures as sharp as that of martensite obtained from quenched highly deformed austenite (Hu and Kallend, 1981, Nunes 1987).

\section{CONCLUSIONS}

1. As a result of increasing the $B$ content from 5 to $20 \mathrm{ppm}$, polygonal ferrite is replaced by bainitic ferrite. The grain size (mean intercept length) decreases from $\sim 3 \mu \mathrm{m}$ in the former to $1 \mu \mathrm{m}$ in the latter.

2. The corresponding textures also became significantly stronger as a consequence of the change in the transformation mode from diffusional (polygonal ferrite) to shear (bainite). This texture is believed to have been inherited from the highly deformed unrecrystallized austenite resulting from controlled rolling.

3. The stronger textures of the steels containing bainitic ferrite suggest that selection of variants in the orientation relationship existing between ferrite and austenite takes place.

\section{Acknowledgements}

The authors would like to thank Companhia Brasileira de Metalurgia e Mineração (CBMM) for financial support and supply of material. One of them is grateful to PUC-RJ and to CBMM for provision of a studentship at the University of Cambridge.

\section{References}

Bateman, R. M. and Davies, G. J. (1981). Proc. ICOTOM 6, Tokyo 690-702. Brown, A. Garnish, J. D. and Honeycombe, R. W. K. (1974). Metal. Sci. 8, 317. Bunge, H. J. (1969). Mathematische Methoden der Texturanalyse. Akademie-Verlag Berlin.

Davies, G. J., Kallend, J. J. and Morris, P. P. (1976). Acta Met. 24, 159.

Davies, G. J. and Bateman, R. M. (1981). Proc. ICOTOM 6, Tokyo 132-148.

Hu, H. and Kallend, J. S. (1981). Proc. ICOTOM 6, Tokyo 164-180.

Hulka, K., Heisterkamp, F., Bergmann, B., Barthold, G., Busch, J., Jungblut, H. A., Rios, P. R., Viana, C. S. and Frantov, I. I. Controlled Rolled Low-C. Bainitic Pipe Plates. Niobium Technical Rep. Niobium Products Company GmbH. To be published.

Kallend, J. S. (1970), Ph.D. Thesis Cambridge. 
Lopta, S. L. and Kula, E. B. (1962). TMS-AIME, 865.

Maitrepierre, Ph., Thivellier, D. and Tricot, R. (1975). Met. Trans. 6a, 287.

Nunes, J. R. (1987). M.Sc. Thesis. COPPE/UFRJ Brazil.

Rios, P. R. (1986). Ph.D. Thesis Cambridge.

Roe, R. J. (1965). J. Appl. Phys. 36, 2024.

Yutori, T. and Ogawa, R. (1981). Proc. ICOTOM 6, Tokyo 670-690. 